\title{
Transformational Leadership of Afghans and Americans: A Study of Culture, Age and Gender
}

\author{
Belal A. Kaifi ${ }^{1}$, Bahaudin G. Mujtaba ${ }^{2}$ \\ ${ }^{1}$ Franklin University, Columbus, USA; ${ }^{2}$ Nova Southeastern University, Fort Lauderdale, USA. \\ Email: belalkaifi@yahoo.com,mujtaba@nova.edu
}

Received October 22 ${ }^{\text {nd }}, 2009$; revised November $29^{\text {th }}$; accepted January $3^{\text {rd }}, 2010$.

\begin{abstract}
Afghans and Americans have been exposed to different leadership styles which may have influenced their orientation on leading others. Age, gender, and/or culture are possible factors for such differences in leadership orientations. This research surveyed the responses of 502 Americans and 300 Afghans to better understand their orientation toward transformational leadership. The Afghan respondents had significantly higher scores for transformational leadership orientation. Female American respondents had a significantly higher transformational leadership orientation than their Afghan female colleagues. Younger Afghans had a significantly higher tendency toward a transformational leadership orientation than their American counterparts. Suggestions for managers and implications for future research are presented.
\end{abstract}

Keywords: Afghans, Americans, Afghanistan, Gender, Age, Culture, Leadership, Ethics

\section{Introduction}

Culture, age group, and gender may influence a person's leadership style and overall change management approach. Leaders must believe in change in order for there to be a better future for a society or organization. "In highly competitive, rapidly changing environments, caring and appreciative leaders are the ones to bet on for long-term success" [1]. The $21^{\text {st }}$ century leader must be equipped with the right tools to be effective, empathic, and efficient in all aspects of the workplace. Today's competitive workplace requires more transformational leaders as they tend to influence workers more positively. Rhodes, Walsh, and Lok state, "While leaders initiate and drive organizational change, they manage the change only with the help of other change agents. These change agents operate with different change skills and competencies depending on particular requirements and circumstances" [2]. Pounder explains that the effect of transformational leadership on subordinates centers on three leadership outcomes: a) the ability of the leader to generate extra effort on the part of those being led, b) subordinates' perception of leader effectiveness, and c) their satisfaction with the leader [3]. Furthermore, "Bass and his associates' views on morality relative to transformational and transactional leadership do suggest that transactional leaders would be expected to engage in unethical practices more so than transformational leaders," and further state that “Judgments of a leader's ethi- cal posture may play a particularly strong role in influencing follower satisfaction with the leader" [4]. Franken, Edwards, and Lambert explain how "Business leaders are under constant pressure to comply with their demands while maintaining the organization's competitiveness in increasingly complex markets" [5]. Transformational leaders are expected to not only to control, lead, plan, and organize, but also motivate, empower, and build healthy relationships with their peers throughout an organization.

A study by Mujtaba and Kaifi illuminated how Afghan leaders have higher scores on the relationship orientation which relates to better job performance [6]. The skills of building and maintaining a healthy relationship is an important element of not just performance but also transformational leadership, especially when one has to create a win-win relationship between employees, vendors, and other stakeholders in the community or local governments. "Over the last decade, considerable research effort has been invested into understanding the processes through which transformational leadership positively relates to follower attitudes, behavior, and performance" [7]. When exploring the conditions under which transformational leadership weaves its effects on performance, research results show that transformational leadership relates to follower identification with work unit and self-efficacy, to predict individual performance, thus representing a moderated mediation effect [7]. Another 
study demonstrated "that instructors displaying transformational leadership qualities in the classroom had a positive and significant influence on student perception of classroom dynamics measured in terms of the three leadership outcomes: extra effort, effectiveness, and satisfaction" [3]. The results appear to be consistent with other findings on transformational leadership which suggest that employees view this style "positively in terms of effectiveness, satisfaction, and motivation to expend effort" [3]. Other researchers argue that "the proposed association of transformational and transactional leadership has been one of augmentation. The augmentation hypothesis argues that transformational leadership will significantly predict leadership criteria after controlling for transactional leadership" [4]. Of course, effective leaders use a variety of methods to influence their followers and some researchers claim that "employees with higher levels of power distance orientation are less likely to be influenced by transformational leadership behaviors alone and may instead need to be led via different or additional leadership styles” [8]. Kirkman et al., further state that "individual-level cultural value orientations, and particularly power distance orientation, should not be ignored in studies of the impact of transformational leadership on followers across cultures" [8]. This study focuses on the leadership style of people in Afghanistan and the United States because an individual's culture might very well be a factor in their influencing style. In both cultures, followers respect managers who are perceived to be just, fair, and ethical. Leaders who do the right thing are able to enhance the morale of their employees because all individuals want to be associated with good causes and institutions that take society's needs into consideration. Transformational leaders must have an ethical intention in order to be followed and respected.

Ricoeur states, "Let us define 'ethical intention' as aiming at the 'good life' with and for others, in just institutions" [9]. The ethical intention is what transformational leaders strive for in organizations of the $21^{\text {st }}$ century because in order for an organization to be successful, there must be unity and collectivity along with just practices. When aiming at the good life, leaders must consider not only themselves but how each person can make a difference by being more understanding, ethical, and concerned for the welfare of all people within an organization. Ricoeur explains, "the good is not contained in any particular thing. The good is rather that which is lacking in all things. This ethics in its entirety presupposes this nonsaturable use of the word predicate good" [9]. Ricoeur recognizes the importance of being ethical and the positive implications it has on daily actions of an organization. In an organization, every conversation can be meaningful, and may bring one that much closer to a good life by learning about the other. Ricoeur states, "To narrate and to follow a story is already to 'reflect upon' events with the aim of encompassing them in successive totalities" [10]. Being able to listen, understand, and communicate to a colleague is important for a transformational leader and will benefit an organization by building trust, friendships, awareness, and respect. As Ricoeur explains, "the good life is for each of us, the nebulus of ideals and dreams of achievements with regard to which a life is held to be more or less fulfilled or unfilled" [9]. In organizations, transformational leaders need to understand others by focusing on solicitude, building friendships, and emphasizing equality because Ricoeur explains, "equality, however it is modulated, is to life in institutions what solicitude is to interpersonal relations" [9]. By having an ethical intention, a transformational leader is able to lead by example. While the controversy regarding whether leaders are products of nature or nurture continue to live on, one element that is clear is how all people are influenced by their specific culture, age group, and gender.

\section{Leadership and Culture}

Culture, or the way people behave in an organization can influence how a leader evaluates performance. Rhodes, Walsh, and Lok state that the "development of a high-performance culture requires the inspiration, drive, and commitment of the leader, leadership is critical to the change process underpinning the Balanced Scorecard" [2]. Furthermore, according to these authors, cultural values tend to have important implications on management practices, because "there is a positive relationship between a high performance culture and the adoption of best practices" [2]. For example, the United States' culture is considered to be high performance and, if organizations are to remain competitive, they must adopt best practices from around the globe. Some of these best practices may include the training and development of effective ethical leaders through succession planning and development because effective leaders require vision, knowledge, and execution skills.

Leaders come in many shapes, forms, and styles which is why transformational leadership has been studied over the years. For example, Kim claims that "there may be at least two different leadership styles in groupthink: the lack of impartial leadership and laissez-faire” [11]. Others state that "In combination with the provision of autonomy, the team leader functions as a supportive member" [12]. Kaifi explains how a transformation leader should consider "the primary tasks of the organization by figuring out the most efficient, effective, and productive way to complete all tasks [13]. Daniel and Davis emphasize that "Managers who lead high-performance teams in highly competitive industries must 
balance complex interpersonal relationships with corporate deadlines" [14]. Teamwork is critical for success in the modern workplace because fast and effective solutions to conundrums require the creativity and talents of all stakeholders. According to Pryor et al., "It is imperative that managers, team leaders, and team members understand the elements required for team success and the potential for team failure" [15]. Kearney proposes that transformational leadership in the modern workplace "will engender positive effects on team performance only to the extent that the team members regard it as legitimate and appropriate that one person among them, the leader, occupies a privileged position” [16]. As such, this study proposes the following hypothesis:

Hypothesis 1 - Afghans and Americans will have similar transformational leadership scores.

\section{Leadership and Gender}

Males and females may lead from different perspectives and these diverse leadership perspectives can lead to different approaches to problem-solving. "Current psychological research on leadership and team interaction suggests that men and women exhibit different leadership styles and interpersonal communication styles in a variety of small-group situations from student problemsolving situations to industry and community situations" [17]. Lantz writes that "women executives are much more likely than males to be a department head or to fill some other staff position, whereas men are much more likely to be chief executive officer (CEO), chief operating officer (COO), president, or vice president” [18]. Many believe that the glass ceiling phenomenon continues to play a role in today's workforce. For example, Babcock explains that "Rather than intentional acts of bias, second-generation gender biases reflect the continuing dominance of traditionally masculine values in the workplace" [19]. Women are perceived to be too emotional and less competitive than men. For example, some authors have written that "Women are significantly more risk averse, tend to be less overconfident and behave less competitively oriented" [20]. Overall, there is a disparity between the equal promotion of men and women to higher positions: "Despite high-profile success stories of female CEOs such as Meg Whitman of eBay, only a handful of Fortune 500 firms in 2008 have a woman in the top spot. Consequently, concern remains about the progress women are making” [21]. Some of the biases are very subtle and not necessarily as blatant as they used to be, which may be a result of human resource professionals doing a more effective and meticulous job of making their managers aware of the existing equal opportunity employment laws in the United States. However, "Workplace inflexibilities and lack of organizational support are driving women away, creating a leaky pipeline of female talent” [22]. If there are biases in the promotion of female candidates, there will be fewer role models for others to follow who are interested in following in their footsteps. This phenomenon is likely to be just as true in Afghanistan as it is in the United States. "In gender studies of public administration, there is significant evidence that women have less organizational power than men, measured in lower pay, fewer career opportunities, and underrepresentation at the highest leadership levels” [23]. As such, this study proposes the following hypotheses:

Hypothesis 2 - Afghan and American males will have similar transformational leadership scores.

Hypothesis 3 - Afghan and American females will have similar transformational leadership scores.

\section{Leadership and Perceptions of Age}

Leaders and styles of leadership may vary based upon age groups. Some authors have written that "With an older leader, the team may be more open to a leader's transformational behaviours, because the team members may be more accepting of the leader's special status" [16]. Kearney further comments that: Results indicate that it makes a difference whether transformational leadership is provided by a leader who is older than or about the same age as the followers. Only in the former case was there a positive relationship between transformational leadership and team performance. Moreover, the data yielded no evidence for a curvilinear effect. [16].

According to Van Vugt, “Age relates to leadership in a complicated way, according to the psychological literature. Some research finds a positive correlation between age and leadership, whereas others find a zero or negative correlation" [24]. Age makes a difference if the leader is respected for his or her knowledge, expertise, overall wisdom, and communication or listening skills. For example, "Experience in Britain suggests that there is a growing confidence that an effective coach working with senior people can achieve positive results, provided he or she has the ability to listen" [25]. Leaders must demonstrate that they are intelligent and capable of making decisions: The evolutionary game model also suggests that people who are quicker to recognize a situation as a coordination problem, that requires leadership, emerge as leaders more often. Furthermore, they must convince people that following is the best option. From this, I expect that leadership correlates with intelligence, because it helps in identifying coordination problems as well as in coordinating actions of multiple actors [24].

Besides making intelligent personal and professional decisions, it is also important for younger and older leaders to be seen as generous and fair as "leadership is correlated with traits and behaviors that signal generosity and fairness" [24]. The theory of moral development states that as individuals' age, they are likely to gain more knowledge about right and wrong and fairness. So 
age has positively contributed to wisdom and knowledge of human beings since individuals are able to learn from personal experiences and the observation of others, and ultimately make positive changes to their habits and behaviors. Van Vugt explains that: In ancestral environments, some situations required the possession of unique and specialized knowledge, for example, where to find a waterhole that has not yet dried up. Knowledge about where to go would have been more likely to be held by older and experienced individuals, and, thus leading is expected to correlate positively with age in this domain. In the present time, evidence for this link between age and leadership can still be found in professions that require a considerable amount of specialized knowledge and experience, such as in science, politics, and arts [24].

Of course, "workforce aging is not a new phenomenon, its confluence with other factors such as early retirement programmes and decreased supplies of skilled craft workers appears to be giving the problem an unprecedented significance” [26]. As such, this study proposes the following hypotheses:

Hypothesis 4 - Afghan and American respondents who are 26 years of age and older will have similar transformational leadership scores.

Hypothesis 5 - Afghan and American respondents who are 25 years of age and younger will have similar transformational leadership scores.

\section{Research Methodology}

Afghans and Americans who participated in this study completed a modified MLQ 5X-Short (Multifactor Leadership Questionnaire) survey that was originally developed by Bass and Avolio for leadership studies. The survey instrument used for this study had eleven short questions (see Appendix A) designed for the population. Many transformational leadership researchers (Pounder, 2008; Kearney, 2008; Ling et al., 2008; and Jansen et al., 2008) have used similar instruments to study the leadership styles of various participants. For example, Pounder used a modified version of the MLQ Form 5X-Short which "involved a sample of instructors and undergraduate students in a Hong Kong university business school [3]. Pounder used a version of the Multifactor Leadership Questionnaire that was modified for a classroom situation to better understand the styles of prospective leaders.

The survey questions were set up in a Likert scale format where a response of 1 means "Never" and a response of 5 means the element is "Always" a characteristic of the responder. One of the questions in the survey asked the respondent the following: "I express with a few simple words what we could and should do”, and a different question asked, "I provide others with new ways of looking at puzzling things.” The respondent would rate him or herself from a scale of 1 to 5 in regard to how many words he or she might use to actually express his or her views. The higher the overall mean scores, the more chances that he or she is likely to have a stronger orientation toward a transformational leadership style. One's range for being a transformational leader can be expressed with a score of "Very low" to a score of "Very high" as presented in Table 1.

The survey instrument was distributed to 2,000 Afghans and Americans by using Facebook as a social-networking instrument to get good participation. A total of 300 surveys were completed successfully by Afghans who live throughout the United States and abroad. Furthermore, a total of 502 surveys were completed successfully by American respondents from the United States. So a total of 802 responses, which represents a $45 \%$ response rate, were used for analysis.

The research question for this study is: Do Afghans and Americans have similar or different transformational leadership scores? For this survey, the higher the overall sum of the scores, the more likely that the participant is strongly oriented toward a transformational leadership style.

\section{Results and Analysis}

The responses of 802 Afghans and Americans demonstrate that there is a statistically significant difference in their mean transformational leadership scores $(\mathrm{t}=7.83$; $\mathrm{p}$ $<0.001$ ), as presented in Table 2. Afghan respondents have a significantly higher score on transformational leadership, which means that the first hypothesis, "Afghans and Americans will have similar transformational leadership scores," cannot be supported. While the mean score of Afghan respondents fall in the high range, the American respondents mean score falls in the moderately high range for transformational leadership orientation.

Table 1. Transformational leadership orientation range

\begin{tabular}{cc}
\hline $45-50$ & Very high range \\
$40-44$ & High range \\
$35-39$ & Moderately high range \\
$30-34$ & Moderately low range \\
$25-29$ & Low range \\
$10-24$ & Very low range \\
\hline
\end{tabular}

Table 2. Transformational leadership score by culture descriptive statistics and T-test of two means

\begin{tabular}{cccc}
\hline Culture & Mean & $\begin{array}{c}\text { Standard } \\
\text { Deviation }\end{array}$ & Sample Size \\
\hline Afghan & $41.266^{*}$ & 4.26 & 300 \\
American & $39.6096^{*}$ & 1.612 & 502 \\
\hline
\end{tabular}

$* t=7.83 ; p<0.001$ 
The second hypothesis predicted that "Afghan and American males will have similar transformational leadership scores" and, as presented in Table 3, this study could not support this supposition because male Afghans have a significantly higher score than their American counterparts.

The third hypothesis predicted that "Afghan and American females will have similar transformational leadership scores" and, as presented in Table 4, this study could not support this supposition because American females' mean score is significantly higher than their female Afghan counterparts.

The fourth hypothesis predicted that "Afghan and American respondents who are 26 years of age and older will have similar transformational leadership scores" and, as presented in Table 5, this study could not support this supposition because older Americans have a significantly higher score than their Afghan colleagues.

The last hypothesis predicted that "Afghan and American respondents who are 25 years of age and younger will have similar transformational leadership scores" and, as presented in Table 6, this study could not support this supposition because the scores are significantly different. Younger Afghans have a significantly higher transformational leadership score than their American colleagues.

Table 3. Transformational leadership score of males descriptive statistics and T-test of two means

\begin{tabular}{cccc}
\hline Males & Mean & $\begin{array}{c}\text { Standard } \\
\text { Deviation }\end{array}$ & $\begin{array}{c}\text { Sample } \\
\text { Size }\end{array}$ \\
\hline Afghan Males & 44.7933 & 2.18689 & 150 \\
American Males & 39.54 & 1.75 & 280 \\
\hline
\end{tabular}

$t=27.2 ; p<0.001$

Table 4. Transformational leadership score of females descriptive statistics and T-test of two means

\begin{tabular}{cccc}
\hline Females & Mean & $\begin{array}{c}\text { Standard } \\
\text { Deviation }\end{array}$ & $\begin{array}{c}\text { Sample } \\
\text { Size }\end{array}$ \\
\hline Afghan Females & 37.74 & 2.56049 & 150 \\
American Females & 39.7 & 1.41 & 222 \\
\hline
\end{tabular}

$t=-9.48 ; p<0.001$

Table 5. Transformational leadership score by age descriptive Statistics and T-test of two means

\begin{tabular}{cccc}
\hline Age & Mean & $\begin{array}{c}\text { Standard } \\
\text { Deviation }\end{array}$ & $\begin{array}{c}\text { Sample } \\
\text { Size }\end{array}$ \\
\hline Older Afghans & 37.36 & 2.097 & 50 \\
Older Americans & 39.59 & 1.64 & 302 \\
\hline$t=-8.53 ; p<0.001$ & & &
\end{tabular}

Table 6. Transformational leadership score by age descriptive statistics and T-test of two means

\begin{tabular}{cccc}
\hline Age & Mean & $\begin{array}{c}\text { Standard } \\
\text { Deviation }\end{array}$ & $\begin{array}{c}\text { Sample } \\
\text { Size }\end{array}$ \\
\hline Younger Afghans & 42.048 & 4.15 & 250 \\
Younger Americans & 39.645 & 1.57 & 200 \\
\hline
\end{tabular}

$t=7.99 ; p<0.001$

This study has demonstrated that Afghans and Americans have significantly different transformational leadership scores. The Afghan respondents scored in the higher range for having a transformational leadership orientation. This finding corroborates Kaifi's study which explains how most Afghans are natural transformational leaders partly because they have been influenced by leaders who have fought for reform, modernization, and a prosperous vision for Afghanistan [27]. Furthermore, there was a statistically significant difference between the scores of Afghans and Americans based on gender and age. Female American respondents as well as older American respondents had a significantly higher transformational leadership orientation than their Afghan colleagues. Younger Afghan respondents as well as male Afghans had a significantly higher tendency toward a transformational leadership orientation than their American counterparts.

\section{Implications of the Study}

This study has demonstrated that Afghans seem to be naturally oriented toward transformational leadership tendencies. From an ideological perspective, Afghans are inclined to be transformational leaders because the Afghan culture places a considerable emphasis on respecting elders because of their knowledge, wisdom, and experience, which explains why older transformational leaders are usually more successful in influencing the Afghan population. This research has shown that young Afghan respondents are even more inclined to be transformational leaders than their older counterparts. Global business and human resource management practices can be challenging when an organization is working with people of a different culture [28]. Organizations that are interested in conducting business in Afghanistan or around the globe should feel confident in hiring an Afghan to lead the organization, which contradicts the current frame of thought.

Due to societal conditioning and cross-cultural tendencies of human nature, some managers assume that employees from high-context cultures such as Afghanistan are likely to be more relationship-oriented which may distract employees from not completing their tasks in a timely manner. For example, they may not be assertive enough to pressure their peers toward being more productive when there is a backlog or even to ask for 
help when necessary because they do not want to appear "pushy" or "rude." Of course, such assumptions are often wrong as the Afghan respondents in this survey have higher transformational leadership scores when compared to their American counterparts.

These results are important elements for multinational managers, administrators of USAID (the United States of America's International Development) agency, NGOs (non-governmental agencies), and other contractors recruiting professionals for jobs and assignments in and around Afghanistan. As a matter of fact, "Afghan leaders from all professions have started emerging. There are currently many Afghan-American medical doctors, engineers, attorneys, professors, police officers, and many who work in either the private or public sectors of the workforce" [29]. The modern workplace for a multinational firm can be very diverse as the workforce today is filled with people from many different leadership styles. Kaifi explains how using multiple frames to evaluate an organization will help a transformational leader understand complex issues within an organization and will result in continuous improvements [13]. As such, "administrators must be managers of diverse interests" and "this necessity grows out of the relativity of values and the pluralization of society" [30]. Managers should provide a better understanding of their rules and policies along with diversity education for all their employees [31]. It is for certain that Afghans and Afghan-Americans bring diverse views and perspectives with an orientation toward transformational leadership into the workplace which can help make them ethical and respected leaders within their teams, departments, organizations, and communities.

In all organizations, there is a high-demand for transformational leaders because of organizational changes due to technology, globalization, and competition. For example, radiology departments throughout America have implemented digital technology (digital images) that has replaced the analog technology (x-rays). During this organizational change, transformational leaders were tasked with successfully implementing this new technology which is why "organizations are quick to look for leaders who are great communicators, visionary thinkers, and who can also get things done and follow through" [32]. It is important for a transformational leader to first understand the organizational culture and gain the trust of subordinates in order to effectively reframe, implement new strategies, and transform an organization to be able to compete in today's global economy.

A research study by Morhart, Herzog and Tomczak suggests "that managers should make a paradigm shift from a TRL [transactional leadership] to a TFL [transformational leadership] philosophy" and go on to say, "At first glance, specifying behavioral codices and scripts for employees dealing with customers and then monitoring and rewarding appropriate demeanor might seem to be an easy solution for obtaining adequate performance from employees representing the corporate brand" [33]. They further mention that:

However, we found that a highly transactional style was counterproductive in terms of followers' motivational condition. Managers would do much better by opening their minds to a TFL approach, which would entail behaviors such as articulating a unifying brand vision, acting as an appropriate role model by living the brand values, giving followers freedom to individually interpret their roles as brand representatives, and providing individualized support by acting as a coach and mentor. This would allow followers to experience the feelings of relatedness, autonomy, and competence in their roles as brand representatives, which would ultimately spill over into the commitment, authenticity, and proactivity that characterize a real brand champion [33].

While transactional leadership styles might be appropriate for specific organizations and situations such as in hospitals experiencing technological changes, this style is usually effective only in the short-term and may not serve a developmental objective. As such, transformational leadership is usually the best alternative for long-term success in employee development situations and when one is trying to inspire and motivate. Research shows that "although employees were more likely to have higher levels of power distance orientation in the PRC [People's Republic of China] than in the U.S., individuals in both countries reacted differently to transformational leadership on the basis of their individual power distance orientation" and furthermore, "irrespective of country-level cultural variation, transformational leadership is especially important for managers whose employees have a low power distance orientation" [8]. A different study explains that, "to be effective, transformational leaders must develop high quality leader-follower relationships, both LMX [Leader-Member Exchange] and interactional justice, with followers. In this sense, leaders must treat followers with kindness and fairness, develop meaningful social exchange relationships (e.g., trust, professional respect) with them, and maintain equitable exchanges with them" [34]. Justice, fairness and good ethical values are important for all leaders, regardless of their cultural orientation. In a highly just and ethical environment, employees will be more committed and motivated to do what is right for the company and their customers. Fisher explains that "Transformational leadership goes beyond the idea that workers are motivated by rewards and punishments by considering other motivators for effective performance” [35]. Transformational leaders must also create an organizational culture where people feel free to think, discuss and express their new ideas. Furthermore, in such an environment: 
Managers need to be mindful that selecting employees on the basis of their learning orientation alone will not guarantee creativity. It is building the creative selfefficacy of their employees that will provide the facilitating conditions for the learning orientation to take hold and bring forth creativity. Managers can be instrumental here in terms of providing an environment that stimulates and nourishes creative self-efficacy, through, for example, applying transformational leadership principles [36].

The $21^{\text {st }}$ century requires transformational leaders who are able to help organizations thrive, continuously improve, and accomplish its goals.

\section{Limitations of the Study}

There are some limitations to this study and one is the modified MLQ 5X-Short (Multifactor Leadership Questionnaire) survey used for this research. This short survey can be combined with other more comprehensive instruments to enhance and confirm the results. Future studies can duplicate the research with a greater number of Afghan participants that are compared to other ethnicities. The fact that this study was conducted with a convenient sample population, living in urban areas and included expatriate Afghans living outside of Afghanistan, was a further limitation. This point is particularly important for the Afghan respondents, who consequently, may have become more "westernized" as a result of living and working in foreign locations. Future studies might control this variable by expanding the research population to include respondents from within Afghanistan. Finally, future researchers should consider translating the survey instrument into Persian and Pashto languages so as to facilitate the test subjects' preferred and dominant reading skills.

\section{Conclusions}

This study focused on the Afghan and American population to compare and better understand their transforma tional leadership tendencies. The premise of the study was to determine if Afghans and Americans have similar transformational leadership scores and this study has confirmed that their scores are significantly different in regard to culture, age, and gender. From a cultural perspective, the results demonstrated that the Afghan respondents scored in the high range and the Americans scored in moderately high range for transformational leadership orientation. From gender and age perspectives, female and older American respondents had a significantly higher transformational leadership orientation than their Afghan colleagues. Younger, as well as male, Afghans had a significantly higher tendency toward a transformational leadership orientation than their American counterparts.

It is important for transformational leaders to understand the organizational culture, provide fair promotional opportunities for both males and females, remain ethical and expect high moral standards, respect people of all ages, and gain the trust of subordinates in order to successfully compete in today's global economy.

\section{REFERENCES}

[1] J. M. Kouzes and B. Z. Posner, "Encouraging the heart," Jossey-Bass, San Francisco, 2003.

[2] J. Rhodes, P. Walsh, and P. Lok, "Convergence and divergence issues in strategic management - Indonesia's experience with the balanced scorecard in HR managementm," The International Journal of Human resources Management, Vol. 19, No. 6, pp. 1170-1185, 2008.

[3] J. Pounder, "Transformational leadership: Practicing what we teach in the Management classroom,” Journal of Education for Business, Vol. 84, No. 1, pp. 2-6, 2008.

[4] R. Vecchio, J. Justin, and C. Pearce, "The utility of transactional and transformational leadership for predicting performance and satisfaction within a path-goal theory framework," Journal of Occupational and Organizational Psychology, Vol. 81, No. 1, pp. 71-82, 2008.

[5] A. Franken, C. Edwards, and R. Lambert, "Executing strategic change: Understanding the critical management Elements that lead to success," California Management Review, Vol. 51, No. 3, pp. 49-73, 2009.

[6] B. G. Mujtaba and B. A. Kaifi, "Afghan and American professionals' leadership orientation toward tasks and relationships: Are there tendencies toward convergence or divergence?” Fortune Journal of International Management, Vol. 5, No. 1, pp. 107-125, 2008.

[7] F. Walumbwa, B. Avolio, and W. Zhu, "How transformational leadership weaves its influence on individual job performance: The role of identification and efficacy beliefs,” Personnel Psychology, Vol. 61, No. 4, pp. 793-825, 2008.

[8] B. Kirkman, G. Chen, J. Farh, Z. Chen, and K. Lowe, "Individual power distance orientation and follower reactions to transformational leaders: A cross level, crosscultural examination,” Academy of Management Journal, Vol. 52, No. 4, pp. 744-764, 2009.

[9] P. Ricoeur, "Oneself as another," University of Chicago Press, Chicago, 1992.

[10] P. Ricoeur, “The narrative function,” John B. Thompson, Ed., Cambridge University Press, Cambridge, pp. 274296, 1982

[11] Y. Kim, “A comparative study of the 'Abilene Paradox' and 'Groupthink',” Public Administration Quarterly, Vol. 25, No. 2, pp. 168-189, 2001.

[12] A. Laszlo, K. Laszlo, and C. Johnsen, "From high-performance teams to evolutionary learning communities: New pathways in organizational development," Journal of Organizational Transformation and Social Change, Vol. 6, No. 1, pp. 29-48, 2009.

[13] B. A. Kaifi, “ $21^{\text {st }}$ century leadership in healthcare,” Chapter Twelve in the Pharmaceutical Technician Laboratory Manual by Sandeep Bansal, Jones and Bartlett Publications, Boston, Massachusetts, pp. 90-100, 2009 
[14] L. Daniel and C. Davis, "What makes high-performance teams excel?” Research Technology Management, Vol. 52, No. 4, pp. 40-45, 2009.

[15] M. Pryor, L. Singleton, S. Taneja, and L. Toombs, “Teaming as a strategic and tactical tool: An analysis with recommendations," International Journal of Management, Vol. 26, No. 2, pp. 320-333, 2009.

[16] E. Kearney, “Age differences between leader and followers as a moderator of the relationship between transformational leadership and team performance,” Journal of Occupational \& Organizational Psychology, Vol. 81, No. 4, pp. 803-811, 2008.

[17] J. Winter, J. Neal, and K. Waner, "How male, female, and mixed-gender groups regard interaction and leadership differences in the business communication course," Business Communication Quarterly, Vol. 64, No. 3, pp. 43-58. 2001.

[18] P. Lantz, "Gender and leadership in healthcare administration: 21st century progress and challenges," Journal of Healthcare Management, Vol. 53, No. 5, pp. 291-301. 2008.

[19] L. Babcock, "What happens when women don't ask?” Negotiation, Vol. 11, No. 96, pp. 1-4, 2008.

[20] D. Beckman and L. Menkhoff, "Will women be women? Analyzing the gender difference among financial experts,” Kyklos, Vol. 61, No. 3, pp. 364-384, 2008.

[21] D. Wyld, "How do women fare when the promotion rules change?” Academy of Management Perspectives, Vol. 22, No. 4, pp. 83-85, 2008.

[22] E. Cabrera, "Fixing the leaky pipeline: Five ways to retain female talent," People and Strategy, Vol. 32, No. 1, pp. 40-45, 2009.

[23] S. Portillo and L. Dehart-Davis, "Gender and organizational rule abidance,” Public Administration Review, Vol. 69, No. 2, pp. 339-347, 2009.

[24] M. Van Vugt, "Evolutionary origins of leadership and followership,” Personality\& Social Psychology Review, Vol. 10, No. 4, pp. 354-371, 2006.

[25] W. Altman, "Executive coaching comes of age," Engi- neering Management, Vol. 17, No. 5, pp. 26-29, 2007.

[26] M. Ashworth, "Preserving knowledge legacies: workforce aging, turnover and human resource issues in the US electric power industry,” International Journal of Human Resource Management, Vol. 17, No. 9, pp. 1659-1688, 2006.

[27] B. A. Kaifi, “A transformational leader,” Sitara Magazine, Vol. 1, No. 4, pp. 48-50, 2008.

[28] G. Karadjova-Stoev and B. G. Mujtaba, "Strategic human resource management and global expansion lessons from the Euro disney challenges in France," International Business and Economics Research Journal, Vol. 8, No. 1, pp. 69-78, 2009.

[29] B. A. Kaifi, "The impact of 9/11 on Afghan-American leaders,” Xlibris, Bloomington, 2009.

[30] T. Cooper, “The responsible administrator ( $4^{\text {th }}$ ed.)," Jossey-Bass, San Francisco, CA, 1998.

[31] B. A. Kaifi and B. G. Mujtaba, "Workforce discrimination: An inquiry on the perspectives of Afghan-American professionals,” Journal of Business Studies Quarterly, Vol. 1, No. 1, pp. 1-15, 2009.

[32] T. Rath and B. Conchie, "Strengths based leadership," Gallup Press, NY, 2009.

[33] F. Morhart, W. Herzog, and T. Tomczak, "Brand-specific leadership: Turning employees into brand champions," Journal of Marketing, Vol. 73, No. 5, pp. 122-142, 2009.

[34] M. Carter, A. Jones-Farmer, A. Armenakis, H. Field, and D. Svyantek, "Transformational leadership and followers' performance: Joint mediating effects of leader-member exchange and interactional justice,” Academy of Management Conference Proceedings, Chicago, United States, 2009.

[35] E. Fisher, "Motivation and leadership in social work management: A review of theories and related studies," Administration in Social Work, Vol. 33, No. 4, pp. 347-367, 2009.

[36] Y. Gong, J. Haung, and J. Farh, “Employee learning orientation, transformational leadership, and employee creativity: The mediating role of employee creative self-efficacy,” Academy of Management Journal, Vol. 52, No. 4, pp. 7765-7778. 2009 


\section{Appendix A}

\section{Transformational Leadership Survey}

The modified MLQ (Multifactor Leadership Questionnaire) Form 5X-Short measures your leadership capabilities based on different factors related to Transformational leadership. To determine whether you are a transforma- tional leader, circle one of the following options that best describe how you see yourself (or the person that is being evaluated) regarding each statement. For each statement, you can indicate the degree to which you (or the person being evaluated) engage (s) in the stated behavior. A rating of 1 means Never and a rating of 5 means Always with the person demonstrating the specific behavior.

\begin{tabular}{|c|c|c|c|c|c|c|}
\hline \multicolumn{2}{|r|}{ Questions } & \multicolumn{5}{|c|}{ Never...........Always } \\
\hline 1. & I express with a few simple words what we could and should do. & 1 & 2 & 3 & 4 & 5 \\
\hline 2. & I provide appealing images about what we can do. & 1 & 2 & 3 & 4 & 5 \\
\hline 3. & I help others find meaning in their work. & 1 & 2 & 3 & 4 & 5 \\
\hline 4. & I enable others to think about old problems in new ways. & 1 & 2 & 3 & 4 & 5 \\
\hline 5. & I provide others with new ways of looking at puzzling things. & 1 & 2 & 3 & 4 & 5 \\
\hline 6. & I get others to rethink ideas that they had never questioned before. & 1 & 2 & 3 & 4 & 5 \\
\hline 7. & I make others feel good to be around me. & 1 & 2 & 3 & 4 & 5 \\
\hline 8. & I tell others the standards they have to know to carry out their work. & 1 & 2 & 3 & 4 & 5 \\
\hline 9. & I call attention to what others can get for what they accomplish. & 1 & 2 & 3 & 4 & 5 \\
\hline 10. & Others have complete faith in me. & 1 & 2 & 3 & 4 & 5 \\
\hline & Total Score: & & & & & \\
\hline
\end{tabular}

